\title{
Bajo el gobierno de las negras minas Matrimonio y divorcio entre liberados de la costa de África occidental (Río de Janeiro, 1830-1860)¹
}

\section{Under the rule of the black minas: Marriage and divorce among freedmen of the West African coast (Rio de Janeiro, 1830-1860)}

\author{
Juliana Barreto Farias \\ Universidad de Integración Internacional de la Lusofonía Afrobrasileña, \\ Campus dos Malês-Bahia-; \\ Universidade do Estado da Bahia -Campus Salvador-Bahia (Brasil) \\ julianafarias@unilab.edu.br
}

\section{Resumen}

Mi objetivo en este artículo es abordar los procesos de divorcio iniciados por africanas de la costa oeste conocidas en Río de Janeiro (Brasil), como "negras minas", buscando comprender los significados que el matrimonio y el divorcio católicos tenían para estas mujeres, y también para sus cónyuges. De esta manera, también surgen otras preguntas: ¿hasta qué punto las denuncias de las minas se acercaron -o se alejaron- de las realizadas por mujeres de otros "colores", orígenes y condiciones sociales? ¿Qué revelaron estas disputas sobre las nuevas y viejas formas de identificar a estas africanas? Para tratar de responder a estas preguntas, me voy a basar un conjunto de 19 acciones abiertas entre los años 1830 y 1860, en las que casi todos los involucrados - esposos, esposas y también muchos testigos - eran de la región africana conocida como La Costa de la Mina.

\section{Palabras Clave}

Matrimonio; divorcio católico; "negras minas”; Río de Janeiro.

\begin{abstract}
In this article, I examine divorce processes initiated by African women from the West Coast, known in Rio de Janeiro, Brazil, as "black minas", seeking to understand the meanings that Catholic marriage and divorce had for these women, and also for their spouses. In this way, other questions also arise: to what extent did the denunciations of the minas approach - or move away from - those made by women of other "colors," origins and social conditions? What did these disputes reveal about the new and old ways of identifying these Africans? To answer these questions, I will draw on a set of 19 open actions between the 1830s and 1860s, in which almost all those involved - husbands, wives and also many witnesses - were from the African region known as the Mina Coast
\end{abstract}

Keywords

Marriage; divorce; black minas; Rio de Janeiro.

\footnotetext{
${ }^{1}$ El artículo fue traducido por Carla Estefanía García y Magdalena Candioti.
}

Esta obra está sujeta a la Licencia Reconocimiento-NoComercial-CompartirIgual 4.0 Internacional de Creative Commons. http://creativecommons.org/licenses/by-nc-sa/4.0/ 


\section{El divorcio católico de mujeres negras}

El matrimonio católico se consideraba una institución "enteramente indisoluble", sin embargo, la Iglesia reconoció que "por muchas razones es posible separar a los cónyuges, en cuanto al toro [cama] o en cuanto a la vivienda, por un tiempo determinado o incierto". En las primeras Constituciones del Arzobispado de Bahía, legislación canónica que se encargaba del tema en Brasil hasta al menos las últimas décadas del ochocientos, estos casos eran cuidadosamente esclarecidos. ${ }^{2}$ En situaciones de "sevicias graves o culposas", por ejemplo, la ruptura estaba asegurada si uno de los cónyuges, "con un gran odio, trate tan mal al otro que, viviendo juntos, corren peligro de muerte o de sufrir un mal grave" (Vide, 2010). ${ }^{3}$

Aun así, estos divorcios solo autorizaban la separación de cuerpos y, cuando se concedían a perpetuidad, la división de bienes era realizada en el ámbito civil. Incluso separada legalmente, la pareja no podía contraer nuevas nupcias. Como la primera unión no había sido anulada - y la anulación se producía solo en casos muy específicos - un nuevo matrimonio sería caracterizado como bigamia, que también era condenada. Además, se recomendaba a los cónyuges divorciados que siguieran viviendo "castamente como casados". No por ello las mujeres renunciaban a deshacer sus relaciones matrimoniales. En varias ciudades brasileñas ellas aparecían como las principales autoras de las solicitudes de divorcio.

En Río de Janeiro, los procesos eran llevados adelante ante el Tribunal Eclesiástico, una instancia de la Iglesia Católica que se ocupaba de los crímenes morales y religiosos de los clérigos, pero también juzgaba las causas de los laicos. Desde el Concilio de Trento (1545-1563), la estrategia de la Iglesia incluyó la defensa del catolicismo también en el frente moral, familiar y sexual. Así, entre sus tareas se encontraban velar por la indisolubilidad del matrimonio, la limitación de la "cópula sexual" entre los cónyuges y, sobre todo, la primacía de la castidad (Santana da Silva, 2000). En la ciudad de Río, las deliberaciones en torno a las peticiones de divorcio continuarían como una competencia del Tribunal Eclesiástico al menos hasta las últimas décadas del ochocientos. Se conservan más de 1.500 de estas acciones en los Archivos de la Curia Metropolitana de la ciudad. A pesar de haber tantos registros, prácticamente no tenemos análisis detallados de estos procesos de divorcio abiertos por muchas mujeres en los siglos XVIII y XIX. Y en el caso de libertas y esclavas, los estudios son aún más raros. En Río de Janeiro, la muestra analizada (20 casos) por la historiadora Sílvia Brügger (1995) no incluye mujeres ni hombres negros. Solo

\footnotetext{
2 El término divorcio, utilizado por la Iglesia Católica desde el Concilio de Trento, para designar las separaciones de parejas ratificadas por los Tribunales Eclesiásticos, también fue adoptado por la legislación republicana en Brasil. A partir de 1890, la disolución de la sociedad conyugal también se designó así. La ley de 24 de enero de 1890 -Decreto no 181 del Gobierno Provisional de la Repúblicamantuvo del Derecho Canónico la concepción del divorcio como "vínculo", es decir, admitió la disolución de la sociedad conyugal y la separación definitiva de los bienes, manteniendo, sin embargo, la indisolubilidad del vínculo matrimonial, lo que hacía imposible la formación de una familia legítima por parte de los cónyuges divorciados. El Código Civil de 1916 cambió el término por el de "desquite" (Cortez de Couza, M.,1999).

3 Sobre el matrimonio, ver: Castelnau-L'Estoile (2011).
} 


\section{Bajo el gobierno de las negras minas. Matrimonio y divorcio entre liberados de la costa de África occidental (Río de Janeiro, 1830-1860)}

más recientemente, la investigadora estadounidense Sandra Graham (2011, 2012), en un artículo publicado en la revista brasileña Áfro-Asia, examinó más de cerca un proceso de separación que involucró a una pareja de libertos de África Occidental que vivían en la capital carioca del siglo XIX.

En vista de estas brechas, mi objetivo en este artículo es precisamente abordar los procesos de divorcio iniciados por africanas de la costa oeste, conocidas en Río de Janeiro como "negras minas", buscando comprender los significados que el matrimonio y el divorcio católicos tenían para estas mujeres, y también para sus cónyuges (Barreto Farias, 2012a, 2012b, 2015).. De esta manera, también surgen otras preguntas: ¿hasta qué punto las denuncias de las minas se acercaron -o se alejaron- de las realizadas por mujeres de otros "colores", orígenes y condiciones sociales? ¿Qué revelaron estas disputas sobre las nuevas y viejas formas de identificar a estas africanas? Para tratar de responder a estas preguntas, me voy a basar un conjunto de 19 acciones abiertas entre los años 1830 y 1860, en las que casi todos los involucrados - esposos, esposas y también muchos testigos - eran de la región africana conocida como La Costa de la Mina. En dos litigios no fue posible descubrir el origen de los "libertos negros". Entre los otros, hubo dos casos de "hombres minas" casados con "criollas" 5 y una pareja formada por un "criollo" y una "cabinda" africana ${ }^{6}$. Los catorce libelos restantes eran de maridos y esposas identificados genéricamente como "minas". En al menos siete de ellos encontré más detalles sobre sus orígenes. Además de dos esposas nombradas como "mina gege" y "mina ussá" (léase haussá), había un hombre "mina nagô". Y otras tres mujeres y dos hombres "minas" que habían salido de Salvador hacia Río de Janeiro y aparecían, a veces, designados como nagôs (nombre por el que se llamaba a los yoruba en la capital bahiana).

\section{"Naciones" africanas}

En los registros del siglo XIX, rara vez aparecían los lugares exactos de donde provenían los africanos. En Río de Janeiro, e incluso en otras partes de Brasil, desde al menos principios del siglo XVIII, la expresión mina y sus variantes (como "nación mina" o "negra mina") designaban esclavizados y liberados africanos de la costa occidental, también llamada en esa época Costa de Mina. La zona debe su nombre a la construcción, en el siglo XV, del Castillo de São Jorge da Mina (o Elmina), un emprendimiento de la Corona portuguesa en la antigua Costa de Oro, actual Gana. En los primeros tiempos del tráfico transatlántico, el término se utilizó para designar a todos los cautivos de diferentes reinos, pueblos y grupos étnicos de la

\footnotetext{
${ }^{5}$ En Brasil, los términos criola y criolo indicaban las mujeres y los hombres hijos de africanos, nacidos en el país.

${ }^{6}$ En el siglo 19 en Río de Janeiro, los esclavos africanos que habían sido enviados al puerto de Cabinda, al norte del río Zaire, eran conocidos como cabindas. (Karasch, 2000; Barreto Farias, Gomes \& Soares, 2004)
} 


\section{Juliana Barreto Farias}

región. Poco a poco, la Costa da Mina empezó a abarcar, más precisamente, la Costa de los Esclavos, es decir, la costa de sotavento del Castillo de São Jorge, que se extendía desde el delta del río Volta, en Ghana, hasta la desembocadura del río Níger en Nigéria. Por tanto, mina señalaba a casi todos los pueblos de la Bahía de Benin, en lo que hoy corresponde a tres países: Togo, Benin y Nigeria.

Por lo tanto, los lugares de donde realmente provenían los negros minas podrían ser bastante diferentes en términos de geografía, grupos étnicos, idiomas, culturas, medio ambiente, prácticas económicas o modelos de organización política. Lejos de guardar correlaciones estrictas con las formas actuales de autoidentificación en las más diversas regiones de la costa occidental - en términos de sus nombres y también de su composición social - la llamada nación mina era tanto una construcción forjada en el ámbito de la trata de esclavos como en la propia experiencia de los africanos. Si bien eran "compulsivamente" designados por el sistema esclavista, los hombres y mujeres así reagrupados adquirieron, paulatinamente, sentido por sí mismos, reformulando sus propias reglas y redefiniendo los límites indicativos de afiliación o exclusión que guiaban el comportamiento de sus miembros y servían para clasificar socialmente a los demás. Así, en un proceso de apropiación, los nombres de las naciones se convirtieron en el punto de partida para la reconstrucción de procesos de identificación más inclusivos. Conviviendo en las calles, fraternidades, fiestas religiosas o grupos de trabajo, los minas encontraban similitudes lingüísticas y de comportamiento, creencias y lugares de origen en común y, a partir de ahí, creaban grupos más amplios y con autoconciencia colectiva (Soares, 2000; Parés, 2006; Law, 2006; Barreto Farias, Gomes \& Soares, 2005).

A lo largo del siglo XIX, los hombres y mujeres "minas" siempre fueron, numéricamente, una minoría en toda la población esclavizada de la capital de Río de Janeiro, ya que los africanos desembarcados en la ciudad eran, en su mayoría, de la costa centro-occidental, como los llamados angolas, benguelas, cabindas, cassanges, congos y rebolos (Karasch, 2000; Florentino, 1997). Entre 1800 y 1843, según los cálculos de la historiadora Mary Karasch, de los más de 600.000 africanos que desembarcaron en Río de Janeiro, solo el 1,5\% eran de la costa (Karasch, 2000). A su vez, los datos provenientes del projecto The transatlantic slave trade, para el período de 1801 a 1825, apuntan 175.200 yorubas desembarcando en Bahía (e identificados allí como nagô) y solo 1.000 en Río de Janeiro. Entre los años 1826 y 1850, 116.200 se quedaron en la capital de Bahía y 28.400 se fueron a Río, al Valle del Paraíba y la región sur en general (Eltis, 2004).

A estos grupos también se sumaron hombres y mujeres esclavizados y libertos que llegaban a la Corte con el "éxodo mina" que partiera de Salvador tras la revuelta de los malês en 1835, trasladando a las calles de Río el miedo que asolaba a la ciudad bahiana. Mientras que los amos temerosos no dudaron en deshacerse de sus cautivos, los Nagô libertos también fueron, con sus propios recursos, a la capital del Imperio. La elección no fue aleatoria: en la primera mitad del siglo XIX, Río de Janeiro era la mayor ciudad africana del mundo atlántico. Y, según el jefe de policía Antônio Simões da Silva, los minas allí ya habían formado una red interprovincial que se 


\section{Bajo el gobierno de las negras minas. Matrimonio y divorcio entre liberados de la costa de África occidental (Río de Janeiro, 1830-1860)}

extendía a regiones más distantes, "quizás utilizando un código secreto impenetrable para las autoridades" (Soares, 2001, 387). Y aunque demográficamente constituían una minoría en la ciudad de Río, se destacaron en diferentes espacios sociales, como en el comercio callejero, en el puerto y en algunos espacios religiosos.

Por lo tanto, en este artículo, sostengo que, para muchos de estos hombres y mujeres "minas", y especialmente aquellos que trabajaron como vendedores en el principal mercado de alimentos en Río de Janeiro - el Mercado de la Candelaria - las uniones matrimoniales formalizadas ante la Iglesia Católica eran esenciales para seguir llevando una vida de respeto, libertad y estabilidad en un "mundo de blancos" tantas veces hostil. Además, también podían asegurar y fortalecer el trabajo conjunto entre los llamados "parientes de nación" (como se llamaba a otros africanos de la misma región, y que no eran necesariamente parientes consanguíneos). Como resultado, el matrimonio también podía aumentar la propia "fortuna" de la pareja, como se expresa en diferentes documentos. Sin embargo, como veremos, si estos lazos y acuerdos se rompían, las parejas, y en particular las mujeres, no dudaban en terminar con los matrimonios. Aunque tuvieran que acudir a la justicia por ello.

Asi, al examinar sus procesos de divorcio y otras fuentes dispersas, como los registros de matrimonio y libertad o los incidentes policiales, es posible conocer en detalle las experiencias y los conflictos matrimoniales de estas parejas. No se trata simplemente de resaltar vidas singulares, sino también de percibir experiencias colectivas, y también de tratar de iluminar contextos y procesos históricos más amplios y complejos (Reis, 2008, 315-316). Y para seguir estas discusiones, también es esencial incorporar, en un examen combinado, los estudios más recientes sobre el matrimonio, las relaciones de género, las mujeres africanas, y también los relativos a la esclavitud urbana y la ciudad de Río de Janeiro.

\section{Matrimonios}

En el siglo XIX, casarse en la Iglesia Católica era una tarea complicada. Para empezar, era necesario abrir un proceso - conocido como baño o dispensa de impedimentos - que acreditara ciertas condiciones básicas que permitieran a la pareja. Entre los requisitos figuraban, por ejemplo, la presentación del certificado de bautismo; prueba de que la persona era libre y la proclamación del matrimonio en misas los domingos y días santos y también en las parroquias donde la pareja había vivido. Pero la gente no tenía todos estos documentos en su poder. Los antiguos esclavos no siempre caminaban con sus cartas de alforría, ni los viudos con los certificados de defunción del cónyuge fallecido. Y como la movilidad de la población era grande, los matrimonios a menudo tenían que ser anunciados en innumerables parroquias, llegando incluso a Portugal y sus posesiones en África.

Con tantos impedimentos, se esperaba desincentivar las alianzas matrimoniales. Pero eso no es exactamente lo que sucedió. Muchas parejas realizaban verdaderos malabares para unirse a la Iglesia o incluso mantener el matrimonio. Cuando no 


\section{Juliana Barreto Farias}

podían reunir toda la documentación, algunos apelaron a testigos confiables y residentes en el mismo lugar. Los más ricos todavía tenían la opción de utilizar garantías monetarias. Sin embargo, como pocos tenían dinero o garantes, algunos novios terminaron reclamando la pobreza y pidiendo la indulgencia de sacerdotes y obispos para la "liberación" de ciertas demandas.

Al final, estas estrategias demuestran que el estatus de "casado" era deseado y valorado. Aún así, pocos terminaron teniendo acceso a él. Según la historiadora Sílvia Brügger, los "recursos" de los que carecían muchas parejas no eran necesariamente los que se gastaban en los procesos (que podían eludirse con cierta facilidad), sino los que podían garantizar la estabilidad de la vida conyugal, en una sociedad profundamente marcada por el movimiento y la inestabilidad. Y tal vez la misma dificultad para contraer y mantener el matrimonio católico justificaba su apreciación.

En cualquier caso, en diferentes estudios sobre Río de Janeiro en el siglo XIX, encontré índices y evaluaciones escasas sobre los matrimonios legalizados en la ciudad. En la obra más completa, la historiadora Eulália Lobo presenta una recopilación de registros de matrimonios realizados en todas las parroquias urbanas y rurales entre 1835 y 1869. A partir de sus análisis, pude ver que, aunque las dificultades no lograron desalentar las uniones en la Iglesia, hubo pocos casamientos en la capital del Imperio, así como en otras ciudades brasileñas. Y eso no es sólo entre negros o mestizos (Lahmeyer Lobo, 1978, 148, 369).

Incluso con la pequeña oferta de pretendientes en la Corte, los hombres y mujeres minas - y también sus descendientes - prefirieron casarse con las parejas de su nación. Al menos en la parroquia de Sacramento.7 Aunque no estaban "cerrados" a otros grupos, tendían a organizarse étnicamente en este y otros mercados de la ciudad, como el trabajo o la libertad, y también en las cofradías católicas, espacios sociales y de ocio. Ahora queda por ver por qué estos antiguos esclavos africanos, que a menudo han llevado una vida en común durante muchos años, decidieron sacramentar ante la Iglesia Católica.

A los ojos de la Iglesia, el matrimonio debía responder principalmente a la necesidad de la procreación de la especie humana. No era por amor que los novios se unían, sino para cumplir con los deberes: pagar la deuda conyugal, procrear y, finalmente, luchar contra la tentación del adulterio. Entre los cónyuges "minas" estudiados aquí, la mayoría ya tenía hijos naturales. Y ninguno de ellos mencionó que otros niños estuvieran entre las prioridades de la pareja. Si no fuera para tener nuevos herederos legítimos o - como veremos - escapar de las relaciones extramatrimoniales, ¿qué llevó exactamente a las minas "frente a la Iglesia"?

Muchos reclamaron el "amor mutuo", la amistad y el "conocimiento prolongado" como sus principales motivaciones para el matrimonio católico. Sin embargo, otras cuestiones estratégicas parecían tener más influencia en las parejas minas. Como fue

\footnotetext{
7 Para un análisis más detallado de estos datos, véase: Farias, 2015, especialmente el capítulo "Trabalho e vida conjugal.
} 


\section{Bajo el gobierno de las negras minas. Matrimonio y divorcio entre liberados de la costa de África occidental (Río de Janeiro, 1830-1860)}

el caso de los vendedores del Mercado de Candelária Fortunata Maria da Conceição y João José Barbosa. Los dos habían convivido durante algún tiempo; mantenían, como se decía en su momento, una "relación ilícita". Y, como se registra en la carta de libertad fechada en 1836, Fortunata, una mina negra, tuvo una hija llamada María. Es muy probable que el africano fuera el padre de la niña. En 1848, durante el desarrollo de la acción de divorcio presentada por ambos, João José solicitó un documento para confirmar que la "llamada inocente María Criolla, hija de Fortunata", era "también su hija legitimada por el posterior matrimonio celebrado" entre ellos. Tal vez esta fue la razón principal - o una de las razones - para legalizar su unión. Según la ordenación filipina y la legislación eclesiástica, el matrimonio de los padres era una forma de legitimar al hijo natural. Llamado legitimación por matrimonio o próximo matrimonio, este mecanismo garantizaba incluso que los hijos reconocidos tuvieran derecho a la sucesión patrimonial ${ }^{8}$.

La liberta "mina jeje" Maria Joaquina afirmó que había sacramentado su relación con el "negro mina" João José Rodrigues, pombeiro ${ }^{9}$ en la plaza del mercado de Río, "sólo por piedad hacia él, que estaba amenazado con ser reclutado para el Ejército, [y] con este favor lo liberó". De hecho, el matrimonio fue una de las condiciones que, según las Instrucciones de 1822 (que estuvieron en vigor hasta 1875), eximía a los hombres del reclutamiento para el Ejército o la Marina. Sin embargo, no sabemos si esto liberó a Jõao José. Además, según las declaraciones de la "negra mina", las razones que llevaron a María Joaquina al casamiento fueron otras: "ciertamente no fue por amor, ni por amistad que lo hizo, sino por su interés y beneficio, o para robarle de cerca la poca fortuna ganada con el sudor de su frente". ${ }^{10}$

En los encuentros y desencuentros conyugales de estos africanos, las mujeres también hablaron de este "interés" por sus bienes y "fortunas". A mediados de la década de 1830, la liberta de Cabinda Rita Maria da Conceição recordó que se había casado con el criollo Antonio José de Santa Rosa, un vendedor de la Plaza del Mercado, por el "amor recíproco" que "se entregaban". Pero, en poco tiempo, el esposo comenzó a brindar "pruebas sensatas de que se había casado con la Demandante no por amistad, sino únicamente por el interés que esta sociedad generó para él, porque todo lo que la pareja tiene es en gran parte propiedad de la Autora". ${ }^{11}$

En la década de 1850, la liberta "nagô" Lívia Maria de Purificación fue más lejos. Cuando conoció a Amaro José de Mesquita, "mina" esclavo del Barón de Bonfim, a

\footnotetext{
${ }^{8}$ Para esta discusión, ver, por ejemplo: da Silva Silveira, 2005, especialmente el capítulo 4.

${ }^{9} \mathrm{~N}$. de T. Pombeiro era comerciante intermediario en el comercio de alimentos entre productores y otros comerciantes o consumidores.

${ }^{10}$ En las consideraciones finales del caso, el abogado de José Rodrigues añadió: "[...] La autora sigue jurando que se casó con el acusado, es que se hizo amiga de ella; los Contendientes saben muy bien que la palabra amistad no es sinónimo del verbo amar o su participio amado, o del verbo que las gramáticas llaman sustantivo; y por lo tanto no vengan a nosotros caracornios, porque tenemos expresiones para repelerlos solamente". Arquivo da Cúria Metropolitana do Rio de Janeiro (de ahra en más ACMRJ), Libelo de Divórcio 1136, 1854, p. 155.

${ }^{11}$ ACMRJ, Libelo de Divórcio 766, 1835, p. 8.
} 
quien servía "como comprador y sirviente de mesa". Pero - según el testimonio de Livia- ya en ese momento Amaro quería "vivir una vida de hogazán, bien presentado y ejercitado en el arte de seducir tanto cuanto, de eso ya hacía su profesión habitual". Tan pronto como la conoció, quedó "deslumbrado" por sus posesiones: doce esclavos, joyas, dinero en la casa del Banco Souto. ${ }^{12}$ Y tanto fue así que entró en "buenas relaciones" con la africana. Poco después comenzaron a relacionarse y él le pidió que le "suministrara" 300.000 réis, cantidad que le faltaba para completar el dinero requerido por su alforria. Ella le dio el monto, pero bajo "condición de matrimonio". Amaro se puso reticente porque supo que, "bien aconsejada", la mujer había decidido hacer un contrato prenupcial. Al final, "decidió a casarse" el 23 de noviembre de 1857. Sin embargo, tres meses después Livia pidió la separación ante el Tribunal Eclesiástico. ${ }^{13}$

Como observaremos más adelante, las mujeres africanas tenían muchas razones para ser tan conscientes de su patrimonio, y el propio derecho civil las protegía en este sentido. Pero no todos tomaron actitudes como la de Livia. ${ }^{14}$ En noviembre de 1857, pocos días antes de casarse, ella y Amaro firmaron un contrato que establecía la unión "de acuerdo con las leyes del país, pero sin comunicación recíproca de bienes, excepto los posteriores al matrimonio y los ingresos que tienen". Alforriado apenas tres días antes de firmar este documento, el "negro mina" no indicaba ningún patrimonio. La africana, a su vez, incluía a sus doce esclavos (que valían 16 contos de réis juntos), dejando fuera los otros bienes enumerados en el proceso de divorcio. Amaro no podía de ninguna manera vender, alquilar o prestar a ninguno de los cautivos. Además, como ya tenía cuatro hijos naturales (uno de ellos de apenas tres semanas de edad y aún por bautizar -y, al parecer, no era hijo suyo), ellos -y los demás que tuviese- serían herederos de todos sus bienes y la mitad de los que adquirieron en la "constancia del matrimonio".15

En los casos citados hasta ahora, seguimos a los africanos hablando directamente sobre las razones que los llevaron al matrimonio católico. Sin embargo, la mayoría de las veces, sus declaraciones están impregnadas de resentimiento y acusaciones mutuas. Aún así, al leer entrelíneas sus testimonios y también los de los testigos en el proceso (en gran parte, vecinos y amigos de la pareja), es posible entender lo que representaba el matrimonio en tiempos de paz conyugal. Además de conferir cierto estatus y también respeto en un "mundo blanco" tan a menudo hostil, reforzó la solidaridad y la asistencia mutua entre estos libertos. Como señala la historiadora Maria Inês Cortês de Oliveira, el matrimonio era caracterizado como un "acuerdo de

\footnotetext{
12 Uno de los testigos de Livia dice: "Sabes al ver que su esposo amenazó a Livia unas cuantas veces, diciendo en una ocasión que solo se consideraba su esposo siempre y cuando ella tuviera el dinero para mantenerlos, porque terminaría yendo a la casa de su ex amo, que no le faltaba nada". ACMRJ, Libelo de Divórcio 1235, 1858, pp. 34-39.

${ }^{13}$ ACMRJ, Libelo de Divórcio 1235, 1858, p. 54.

${ }^{14}$ La historiadora brasileña Sheila de Castro Faria dice que los acuerdos prenupciales no eran infrecuentes en Brasil, aunque no eran la regla. Aún así, sorprende la frecuencia con la que aparecían los alforriados en este tipo de documentos. A pesar de estas afirmaciones, la autora no presenta números ni casos que muestren esta frecuencia (Faria, 2004, p. 2004)

${ }^{15}$ ACMRJ, Libelo de Divórcio 1235, 1854, pp. 9v-10.
} 


\section{Bajo el gobierno de las negras minas. Matrimonio y divorcio entre liberados de la costa de África occidental (Río de Janeiro, 1830-1860)}

apoyo recíproco donde cada uno vela por el otro, contribuyendo a mejorar la calidad de vida de ambos" (Cortês de Oliveira, 1988).

Incluso captadas en momentos de gran conflicto, ciertas escenas descritas en los procesos de separación revelan el cuidado de la salud del otro cónyuge, las preocupaciones por "ganar dinero para la vejez" y, sobre todo, de trabajar juntos con el fin de "aumentar la fortuna de la pareja". Entre los "minas" que he estado analizando, había una especie de acuerdo tácito - que no tardó en formalizarse - que definía que el dinero y los bienes adquiridos por cada uno, y de su propio trabajo, serían de ambos, de la misma manera que los gastos se repartirían equitativamente. Tampoco se dejaron de tener en cuenta las cuestiones relacionadas con los derechos sucesorios, ya que la legalización de los matrimonios garantizaba que el cónyuge sería el heredero legítimo de los bienes de la pareja. Y todo esto parecía tan importante que cuando estos pactos se rompían - o simplemente se resquebrajaban- a menudo resultaban en procesos muy problemáticos.

\section{¿El “hombre en la plaza y la mujer en casa"?16}

Los procesos de divorcio comenzaban con la presentación de una petición al Vicario General del Obispado. Debido a que las mujeres no podían responder por sí mismas las demandas, necesitaban encontrar un abogado o un procurador que las representase. El siguiente paso era la indagación de testigos, generalmente familiares, vecinos $\mathrm{u}$ otras personas cercanas a la pareja. Si se probaban las denuncias, el sacerdote emitía una orden judicial, ordenando que la mujer y los hijos menores de edad (cuando los hubiera) fueran "depositados" en una "casa seria y honesta". A lo largo del proceso, ella podía salir de la nueva morada con el permiso de la Iglesia o de sus actuales "guardianes". Pero estas determinaciones no siempre se siguieron al dedillo: algunas no esperaban el permiso del vicario para abandonar el hogar conyugal. Otras, incluso "depositadas", continuaban trabajando o saliendo solas. Lo cual no siempre agradaba a los maridos.

De todos modos, después de que se hacía el depósito, todavía era necesario enviar una nueva solicitud para que el marido fuera citado y respondiera la demanda. Y se citaban más testigos. Si sus declaraciones no dejaban lugar a dudas sobre la "culpabilidad" del acusado, éste ni siquiera se tomaba el trabajo de declarar ante el tribunal, dejando que la disputa se ejecutara "en rebeldía". A veces incluso se presentaba, pero abandonaba toda oposición "con el pedido de no pagar las costas". Pero los maridos no siempre abandonaron sus defensas tan fácilmente. En algunos casos, encontramos muchas respuestas a las demandas de las mujeres. En esos momentos, solían negar las acusaciones con vehemencia o incluso recurrir a feroces

\footnotetext{
${ }^{16}$ Esta frase - en su versión afirmativa - forma parte de Adágios portugueses, de Antônio Delicado, 1651. Publicaciones como ésta recogían "cristalizaciones de la sabiduría popular" (refranes, proverbios, anexos), que tenían como tema frecuente el matrimonio, y de alguna manera difundían y a menudo también reelaboraban- normas y valores de la moral católica. Citado en: Nizza da Silva, 1984, 157.
} 
contraataques. Así procedió el negro mina João José Rodrigues. Al oponerse a la petición de la mina-jeje liberta María Joaquina, lanzó pesadas ofensas contra la mujer:

[...] Borracha, depravada, vil, libidinosa, sin ceremonia ella levanta sus faldas a la vista de todos, señalando la parte que por honestidad debería esconder, por el contrario, patentizando aquí (dice ella) es el lugar que besan muchos blancos, y quien ella quiera, que el Acusado es un negro como lo son sus esclavos y queriendo ella llevarlos a la cama donde duerme el Acusado nadie es capaz de impedírselos $[. ..] .^{17}$

En general, los malos tratos y las acusaciones de adulterio aparecían precisamente como los principales motivos que llevaban a las mujeres a pedir la separación en el Tribunal Eclesiástico. Sin embargo, las "razones accesorias" explicadas en sus peticiones casi siempre tenían más peso que una alegación de malos tratos fácilmente reconocible. En el caso de las "negras minas", esto es bastante evidente. No es que no se quejaran también de la violencia de sus maridos o de sus numerosas amantes. Al contrario, palizas, ofensas verbales y relaciones extramatrimoniales fueron profusamente mencionadas. Sin embargo, otras cuestiones parecían tan -o más- importantes en las disputas entre los esposos.

Comparando las peticiones de divorcio iniciadas por las africanas "minas", tenemos la impresión de que todas ellas siguieron el mismo guion a la hora de acusar a sus maridos. Aunque la "falta de ocupación" de los cónyuges y la dilapidación del patrimonio de la pareja no figuraban entre las causas legales de divorcio eclesiástico, la mayoría mencionaba situaciones de este tipo. Y también añadía que ese comportamiento "desarreglado" era la causa y/o la consecuencia de muchos adulterios y de una violencia excesiva. Es cierto que las mujeres de otros grupos sociales - incluidas las Doñas de la elite - también se quejaban de la falta de sustento, de la malversación de bienes y de los gastos que hacían sus maridos con sus concubinas. Tanto es así que la propia legislación civil buscaba protegerlas de la acción perjudicial de sus cónyuges. En las Ordenanzas de Filipinas, se determinó que

[...] el marido no podrá vender ni disponer de ningún bien de raíz sin poder o consentimiento expreso de su mujer, ni de los bienes, de los que cada uno de ellos tenga el uso y el fruto únicamente, tanto si están casados por medio de carta, según la costumbre del Reino, como por dote y rescate. Dicho consentimiento no podrá probarse, salvo por escritura pública; y si se hace lo contrario, la venta o enajenación será nula (Mendes de Almeida, 1870).

No obstante, para la Iglesia católica, estas situaciones no eran razones suficientes para que las parejas se separaran. Aun así, en algunos casos, podrían tenerse en cuenta en la conclusión de un proceso. En 1847, la "negra mina" Esméria Alves Correia, arrendataria en el Mercado de la Candelária, solicitó la separación del mina João Pereira porque éste "se había enzarzado en una mancebía con una de las

${ }^{17}$ ACMRJ, Libelo de Divórcio 1136, 1854, p.15 e segs. 


\section{Bajo el gobierno de las negras minas. Matrimonio y divorcio entre liberados de la costa de África occidental (Río de Janeiro, 1830-1860)}

esclavas de la pareja", y estaba dilapidando los bienes de ambos, con gastos en beneficio de esta cautiva, llegando incluso a liberarla. João trató de defenderse, diciendo que -en realidad- los gastos se hicieron para pagar las deudas de su esposa, adquiridas para aumentar su negocio de comestibles en la Praça do Mercado. Incluso adjuntó un recibo con la hipoteca de una esclava "nagô" y su hijo, en caso de que no pagara el préstamo hecho con el comerciante portugués del mercado José da Costa e Souza. Al final del litigio, Esméria obtuvo la separación perpetua, con derecho a la división de los bienes en el tribunal civil. Al concluir, el canónigo justificó su decisión, destacando que

[...] El demandado no probó lo que expuso en su escrito de oposición, pues ni siquiera presentó un testigo, y sólo se conformó con el papel de f. 18 [el recibo de la hipoteca], que no le apoya en lo que afirma, sino que da fuerza a la alegación de A. en el artículo 4o de la demanda, pues, siendo el jefe del matrimonio, sobre él recae toda la buena o mala administración de los asuntos del mismo. ${ }^{18}$

Estos juegos de acusación y defensa entre los minas africanos de Río de Janeiro eran en muchos aspectos similares a los de otros grupos étnicos y sociales en varias ciudades brasileñas. Pero sus disputas maritales tenían algunas particularidades. Y la primera de ellas se vinculaba a los roles sociales otorgados a hombres y mujeres. En sus peticiones de divorcio, las minas también utilizaron toda una retórica para convencer al Tribunal Eclesiástico. Al igual que las brasileñas blancas de diferente condición, las criollas e incluso otras africanas, buscaban mostrar pruebas de su buen comportamiento, porque de esta manera ponían en evidencia los injustos maltratos que recibían de sus cónyuges. "Cumpliendo con todos los deberes de una mujer casada", decían que "guardaban siempre la fe conyugal", viviendo con "la mayor honestidad y modestia, sirviendo a su marido sin darle motivo de la más mínima insatisfacción" y "sin faltar nunca a los preceptos de la moral a los que están sometidas sus costumbres, sin olvidar nunca proceder con toda honestidad". 19

Pero, ¿cuáles eran exactamente esos “deberes conyugales"? Según la Iglesia católica -y, en gran medida, también el Estado- existía una división muy estricta de los deberes en la vida doméstica y privada, que delimitaba los roles sociales de género. Las mujeres, en su expresión ideal, eran responsables de obedecer y ayudar a sus maridos, manteniéndose como esposas fieles y honorables, centradas exclusivamente en el interior del hogar y el cuidado de los hijos, la educación y la

\footnotetext{
${ }^{18}$ ACMRJ, Libelo de Divórcio 1030, 1847, p. 36.

${ }^{19}$ Cf. ACMRJ, Libelo de Divórcio 1174, 1856; Libelo de Divórcio 1136, 1854. Aunque su marido era un esclavo (el criollo Adão), la liberta criolla María Correa Ramos también utilizó este "modelo" de esposa ideal para obtener el divorcio del Tribunal Eclesiástico. En 1796, presentó un libelo en el que afirmaba que "[...] está casada y fue recibida en la faz de la iglesia con el demandado Adão Xavier Criollo por dieciséis años a esta parte, y en todo este tiempo siempre lo sirvió y obedeció con obediencia de esposa a marido, estimándolo en todo, y comportándose en consorcio con todo el honor, y fidelidad debida al tálamo sin nota ni indicaciones contrarias". ACMRJ, Libelo de Divórcio 37, 1796, p. 6.
} 


\section{Juliana Barreto Farias}

salud física y espiritual de la familia. Su honestidad estaba estrictamente ligada al recogimiento, al anonimato, al vivir puertas adentro. Mientras que el hogar representaba el lugar de preservación del honor femenino y, en consecuencia, de su familia, la calle era el espacio de lo deshonesto, de la prostitución. El marido, por su parte, tenía el papel de protector de la familia, responsable de la seguridad física y del sustento económico, y también debía vigilar las acciones de su mujer, pudiendo incluso castigarla (Zanatta, 2005, 57).

De hecho, las relaciones de poder implícitas en la esclavitud también acabaron reproduciéndose en estas relaciones más íntimas. Condenadas a una especie de "esclavitud doméstica", las mujeres debían cuidar de la casa y servir con su sexo a los jefes de familia, dándoles hijos que perpetuaran su descendencia y fueran como modelos de la sociedad familiar soñada por la Iglesia. Sin embargo, al tratarse de representaciones ideales, no se corresponden necesariamente con el "mundo real". Como hemos visto, las libertas "minas" -a través de sus procuradores y abogadosintentaban a toda costa ajustarse a estas normas esperadas por la Iglesia y obtener así el deseado divorcio. Actuaban con cautela dentro de los tenues límites entre acusar y ser acusada, ya que el propio Derecho Canónico reiteraba su situación de inferioridad en las relaciones conyugales y atribuía ciertos privilegios a los hombres. Y los maridos sabían manejar estas normas de conducta a su favor, buscando así escapar de las acusaciones o incluso evitar las separaciones. Eso es lo que vemos en esta historia contada por el pombeiro mina Rufino María Balita.

El 17 de junio de 1856, el pidió al Tribunal Eclesiástico que la "negra mina" Henriqueta Maria da Conceição fuera retirada de la casa donde estaba depositada. Según Rufino, estaba siendo "seducida" por los guardianes de su depósito, el africano Benguela Venâncio Francisco dos Santos y su esposa, la mina Joaquina Mathildes. Aprovechándose de su "belleza y de los rasgos agradables con que la naturaleza la ha dotado", la indujeron a prostituirse y a vivir como ramera, "porque de este arte se aprovechan la misma Joaquina y otras personas, y se enriquecen a costa de la honra del peticionario y de su mujer que hasta ahora ha sido honrada". En vista de ello, pidió al juez que la trasladara a otro lugar, preferiblemente "en poder de personas blancas". ${ }^{20}$ Pero Henriqueta se defendió alegando que:

\footnotetext{
Las personas en cuya casa está depositada fueron padrinos de matrimonio, pobres pero honrados, viven decentemente con el producto de su trabajo, y así el dicho Venancio gana diariamente en el Arsenal de Guerra 2500 y su mujer con las rentas de su quitanda y esclavos gana lo suficiente para subsistir decentemente sin que sea necesario para ello emplear los medios deshonestos que el Demandado mencionó.
}

Al final, la mujer africana acabó quedándose en casa de sus depositarios. Sin embargo, más tarde, contrariando su petición, Rufino volvió a la ofensiva contra la otra "negra mina". Hasta entonces, dijo, su mujer vivía tranquilamente, "cumpliendo

\footnotetext{
${ }^{20}$ ACMRJ, Libelo de Divórcio 1174, 1856, p. 2 (justificación de la retirada de la fianza).
} 


\section{Bajo el gobierno de las negras minas. Matrimonio y divorcio entre liberados de la costa de África occidental (Río de Janeiro, 1830-1860)}

los deberes de una buena esposa". No obstante, últimamente, Joaquina Mathildes la arrastraba a los "bailes y diversiones" nocturnos sin respetarle ni pedirle permiso. Aunque afirmaba que no maltrataba a su esposa (cosa que Henriqueta negaba), solía regañarla, "dándole buenos consejos y mostrándole que ese comportamiento era feo, y no propio de una mujer tan honesta como ella". ${ }^{21}$

Cinco años antes, el "negro mina" José Guilherme también se había quejado del comportamiento de su esposa, la mina quitandeira ${ }^{22}$ Joaquina Justiniana Vitória. Mientras el proceso de separación pasaba por el Tribunal Eclesiástico, ella debía alojarse en el almacén de José Lopes Teixeira Guimarães, en la calle Conceição. Sin embargo, según su marido, Joaquina no estaba allí; de hecho, estaba en su compañía, "yendo y viniendo a su antojo, e incluso empleándose en vender sus quitandas diariamente en el largo do Capim".

Replicando las afirmaciones de José, la africana argumentó que el depositario conocía su probidad y sabía que no podía hacer su quitanda -llamada Angu- en su casa. Así, "por falta de conveniencia para este fin", obtuvo permiso para prepararla en otro lugar, "capaz y honesto". Y en ese nuevo lugar no tenía contacto con José. Sólo que eso no era exactamente lo que estaba diciendo. Rebatiendo una vez más las afirmaciones de Joaquina, recordó que, sólo después de su conflicto, ella dejó de vivir a su lado y se fue a alquilar la casa donde "está viviendo a su gusto, y separada" de él. 23

No es necesario multiplicar los ejemplos que revelan cómo los africanos y africanas minas, cada uno a su manera, usaron y abusaron de estos modelos de la conducta para lograr sus intenciones. Es posible que Rufino y José Guilherme se sintieran molestos por el trabajo y las frecuentes salidas de sus esposas, pero -si examinamos más detenidamente sus declaraciones y otros detalles presentes en las accionesobservaremos que no siempre fue así. Prácticamente todas las minas implicadas en estos procesos estaban acostumbradas a comprar en las calles y mercados de Río desde que eran esclavas. Lejos de lo que proclama la moral católica, no vivían confinadas en sus casas y a menudo mantenían -o seguían manteniendo- a sus hijos y otros familiares por sí mismas. Y, la mayoría de las veces, con el consentimiento y la colaboración de sus propios maridos.

El mina José Guilherme afirmaba haber "consentido que [su mujer] se empleara en el negocio de los comestibles" mientras él, para "aumentar su fortuna", trabajaba como cocinero. La mina Henriqueta Maria da Conceição trabajaba como quitandeira en Largo do Capim desde que era cautiva. El "nagô" Tibério Tomás de Aquino, por su parte, apenas llegado de Bahía, en un momento que no pude pecisar, devino vendedor de pescado en la Plaza del Mercado de Río, antes de casarse con la "nagô"

\footnotetext{
${ }^{21}$ ACMRJ, Libelo de Divórcio 1174, 1856, p. 9-12.

22 N. de T. Quitandeira es un término que designa a una vendedora ambulante de verduras o comidas preparadas o a la persona que está cargo de, o es empleada, de un comercio de comestibles (quitanda).

${ }^{23}$ ACMRJ, Libelo de Divórcio 1097, 1851, p. 25-30; 32.
} 


\section{Juliana Barreto Farias}

Faustina Joaquina Dourado en 1857. Esta última, a su vez, también vendía quitandas en el mismo lugar, probablemente junto a él. ${ }^{24}$

Frente a la Iglesia, estos hombres y mujeres fueron juzgados de acuerdo con las normas ideales de convivencia. No por casualidad, tendían a destacar imágenes sobre sí mismos que a veces no se correspondían con sus experiencias cotidianas. Pero, a diferencia de las disputas de las parejas de la élite o incluso de otras condiciones sociales, pudimos captar, en sus enfrentamientos conyugales, experiencias laborales compartidas y una vida femenina mucho más autónoma. Sin duda, las mujeres minas no se sentían a gusto con los compañeros que no les proporcionaban comida, ropa o pagaban sus alquileres. Al fin y al cabo, eso era lo que, en aquella sociedad, se esperaba de un "buen marido". No por ello dejaron de salir a asegurar el sustento de la familia, a sus "expensas", o de luchar en los tribunales eclesiásticos por sus derechos. Cuando estos lazos conyugales y familiares, lentamente entretejidos, comenzaron a deshacerse, las esposas no escatimaron esfuerzos para romperlos de una vez por todas. En esos momentos, afloraban las quejas y las reivindicaciones. Para estas africanas, ser "tratadas como esclavas” era mucho más que una metáfora de la condición femenina.

\section{Bajo el gobierno de las "negras minas"}

De hecho, las referencias a la esclavitud no fueron fortuitas. En su petición de divorcio, la esclava negra Amélia Maria da Glória dijo que "trabajaba más que una esclava, ya que lavaba la ropa, planchaba y cosía, entregando todo el producto de su trabajo a su marido". En el proceso interpuesto por la nagô Faustina Dourado, uno de sus testigos, el propietario "blanco" Anselmo Luis Ribeiro, dijo que el nagô Tibério Tomás de Aquino le cobraba "todos los días una cantidad como una especie de periódico", y cuando no la recibía, le daba "golpes". La mina negra Izabel Maria da Conceição también declaró que Fortunato Ribeiro, su marido y africano de la misma "nación", alimentaba su adicción al juego con parte del dinero que ella ganaba con sus quitandas y que le exigía cada mañana. Cuando ella no le daba todo, incluso la golpeaba "bárbaramente". 25

Después de tantos años viviendo como cautivas, no esperaban encontrar en sus compañeros réplicas de antiguos amos. Ciertamente, este tipo de quejas no eran exclusivas de las mujeres negras. Las mujeres de otros colores y condiciones también hicieron alusiones de este tipo en sus peticiones de divorcio. En un proceso de 1805, por ejemplo, Sebastiana Rosa de Oliveira se quejaba de que su marido, "además de tratarla como su esclava, haciendo todo el servicio de la casa y del bar que tiene para las bebidas", le exigía que fuera a la playa y al almacén a comprar carbón, pescado o carne, incluso "teniendo esclavos que [podían] servir en este ministerio" (Brügger, 1995). Más que contra el trabajo en sí, Sebastiana parecía

${ }^{24}$ Cf. ACMRJ, Libelos de Divórcio 1907; 1174; 1026.

${ }^{25}$ ACMRJ, Libelo de Divórcio 1316, 1854; Libelo de Divórcio 1277, 1860; Libelo de Divórcio 1204, 1857. 


\section{Bajo el gobierno de las negras minas. Matrimonio y divorcio entre liberados de la costa de África occidental (Río de Janeiro, 1830-1860)}

rebelarse contra la actitud de su compañero. Para Sílvia Brügger, lo que la acercaba a la condición de cautiva era el hecho de no tener libertad de acción y de seguir recibiendo castigos cuando no cumplía con obligaciones que eran de los esclavos o de sus propios maridos. Aunque desempeñaban funciones diferentes, las mujeres morenas y las blancas como ella se consideraban iguales a sus maridos, ya que contribuían de la misma manera o incluso más al establecimiento de la unidad doméstica, ya que, en general, aportaban regalos al matrimonio.

Entre las negras mina, los descontentos eran similares. Sin embargo, para ellas, la esclavitud era una vieja realidad de la que, sólo después de mucho trabajo y energía, había conseguido liberarse. Y, en muchos casos, liberaron a sus propios maridos. Tal vez algunas tampoco querían salir a vender a la calle o a hacer la compra diaria, y por eso adquirían cautivos para realizar estas tareas. Pero la mayoría de ellas, incluso cuando fueron liberadas, siguieron trabajando en pequeños negocios, junto a sus esclavos, sus maridos, otros "parientes de nación" o incluso solas. Entonces, ¿cómo podían aceptar que se las volviera a tratar como cautivas, se las obligara a entregar jornales todos los días como hacían los esclavos de alquiler, y se les diera severos castigos cuando esos jornales no eran considerados suficientes? ¿Cómo podían perder otra vez una libertad tan duramente ganada?

En el Río de Janeiro del siglo XIX, estas mujeres africanas eran reconocidas por su altivez y autonomía. Como "excelentes quitandeiras", recorrieron las calles de la ciudad con facilidad, mantuvieron a sus clientes en el concurrido Mercado de la Candelaria e incluso hicieron "pequeñas fortunas". Tal vez aquí recreaban experiencias vividas -u observadas y aprendidas de sus madres, tías y abuelas- en tierra yoruba, aunque casi siempre decían que ya no podían recordar a sus parientes dejados al otro lado del Atlántico. Allí, las mujeres predominaban en los oficios locales y en las redes de mercado que se extendían desde las pequeñas aldeas hasta las grandes ciudades. Al dominar estos oficios, ganaron independencia, autoridad y riqueza (Graham, 2011; Soares, 2005; Gomes \& Soares, 2002; Faria, 2004; Gomes \& Soares, 2007).

En las sociedades precoloniales yoruba, como señala el historiador Toyn Falola (1995), existía una rígida división sexual del trabajo, en la que los hombres se encargaban de la agricultura y las artesanías y las mujeres de la producción de alimentos y el comercio. Las actividades mercantiles, predominantemente femeninas, también se caracterizaban por sus múltiples facetas, que reflejaban los roles sociales que desempeñaban las mujeres. Las mujeres recién casadas y las de mayor edad, por ejemplo, sólo vendían desde sus propias casas, abasteciendo al vecindario y al comercio local, ya que no podían salir de sus casas para ir al mercado. Las demás, y sobre todo las que tenían hijos mayores, tenían una presencia dominante en los mercados, ya sea diarios, periódicos o de larga distancia. Al monopolizar este universo comercial, podían enriquecerse y, en consecuencia, disfrutar de la importancia sociopolítica asociada a los ricos: adquirir símbolos de estatus como ropa y caballos, coleccionar títulos y lograr adeptos. Sin embargo, señala Falola, la conexión entre el mercado y el poder era aún más amplia que la 


\section{Juliana Barreto Farias}

relación entre la riqueza y el poder. Al controlar los mercados, las mujeres no sólo prosperaron y ganaron más prestigio social, sino que también asumieron los rituales y el simbolismo que allí se desarrolla.

Entre los igbos, grupo étnico que ocupaba zonas cercanas a los yoruba, también se observó este protagonismo de las mujeres en las actividades comerciales. Al investigarlas en la ciudad de Nnobi, en el estado de Anambra (Nigeria), desde el periodo precolonial (antes de 1900) hasta tiempos más recientes, Ifi Amadieu observó el predominio de una división sexual del trabajo profundamente guiada por la deidad Idemili, "gobernante" y figura central del mito de origen de Nnobi. A través de él, se contó que el primer hombre que existió en la ciudad fue el cazador Aho, que pronto conoció a Idemili, con quien se casó y tuvo una hija llamada Edo, también muy bella y trabajadora. El día de su boda, su madre le regaló una "vasija de la prosperidad", que la hizo rica e influyente. Presentada aquí muy brevemente, esta historia puede considerarse una alegoría del papel central de la mujer en esa sociedad. Como señala Amadiume, "el encuentro de lo sobrenatural (la diosa Idemili) y lo natural (el cazador Aho) es una mujer trabajadora: Edo". Como ella, todas las mujeres de Nnobi también habrían heredado de la diosa la perseverancia, el compromiso con el trabajo y la "vasija de la prosperidad".

A excepción del cultivo de batatas, todo el resto de la producción agrícola y la compra y venta de dichos bienes estaba en manos de las mujeres. Mientras los hombres no cocinaban ni ofrecían nada producido por las mujeres, éstas comercializaban productos típicamente masculinos, lo que les garantizaba mayores beneficios y el monopolio de las actividades mercantiles. Así, concluye el autor, el trabajo femenino era estructural y extremadamente valorado en esta sociedad. Los que no ejercían ningún oficio eran despreciados. Aunque un matrimonio con gente rica no era garantía de enriquecimiento. De hecho, se esperaba que las mujeres fueran autosuficientes y alcanzaran la riqueza y el prestigio por sí mismas. En el siglo XIX, era habitual encontrar esposas con más éxito que sus maridos, incluso ayudándoles económicamente. En algunos casos, llegaron a ser tan prósperas y poderosas que los cónyuges ya no eran conocidos por sus nombres, sino por el hecho de estar casados con mujeres notables (Amadieu, 1987).

De un modo u otro, muchos de los minas africanos que vivían en Río también se distinguieron por su determinación y autonomía, por su ingenio y éxito comercial. Posiblemente, esta distinción era fruto de las herencias familiares o de los recuerdos que traían de sus tierras yoruba, donde muchos nacieron o se marcharon a una edad muy temprana. 0 incluso de la convivencia con los nagôs de Bahía, lugar donde muchos de ellos vivieron inicialmente cuando desembarcaron en Brasil. Aun así, más allá de estas herencias o recreaciones de las tradiciones y prácticas comerciales africanas, observé que las Minas negras -y también sus maridos- sabían manejar la legislación y las normas de una sociedad jerárquica a este lado del Atlántico. A diferencia de lo que ocurría con los yoruba y los igbos de la Costa Oeste, entre estos africanos occidentales de Río de Janeiro no había rigidez en la división de las tareas 


\section{Bajo el gobierno de las negras minas. Matrimonio y divorcio entre liberados de la costa de África occidental (Río de Janeiro, 1830-1860)}

que debían realizar hombres y mujeres. Solos o juntos, pretas y pretos minas se ocupaban por igual de las ventas y las quitandas.

En estos acuerdos, el matrimonio -y, en su caso, las segundas nupcias- les parecía fundamental para una vida de trabajo, seguridad, respeto y libertad. La historiadora Sheila de Castro Faria, al analizar los testamentos e inventarios de las forras Minas en Río y en São João del Rei, en la provincia de Minas Gerais, durante el siglo XVIII y la primera mitad del XIX, constató que muchas preferían no casarse y seguían optando por vivir con otra familia, formada con sus esclavos y sus hijos. Además de liberarlas, intentaron enseñarles un modo de vida más adecuado y a seguir conservando su patrimonio en manos femeninas (Faria, 2004). Sin embargo, como hemos visto, no todas optaron por seguir este patrón familiar. Especialmente las que trabajaban como quitandeiras en las calles o en la Plaza del Mercado de Río de Janeiro.

Lejos de las complicadas exigencias matrimoniales, la liberta Minas Emília Soares do Patrocínio comenzó a trabajar en la década de 1830 en un puesto de la plaza con su primer marido, también él mina, Bernardo José Soares. Tras su muerte, Emília continuó allí e incluso alquiló dos locales más. En la década de 1850, se casó de nuevo, esta vez con Joaquim Manuel Pereira, también mina. Con él, y recurriendo también al trabajo de muchas esclavas minas, siguió vendiendo frutas, verduras y hortalizas en el mismo lugar hasta 1885, año de su muerte. Tras cincuenta años de actividades compartidas, sus hijos, nietos y su marido Joaquim heredaron un significativo patrimonio. Para mujeres como ella, el matrimonio significaba, entre otras cosas, seguridad y el fortalecimiento de un trabajo conjunto entre "parientes de nación". Y esto era tan importante que cuando cualquier desavenencia empezaba a deshacer estos acuerdos tácitos, no dudaban en romperlos de una vez por todas. Para ello, disponían de un mecanismo prácticamente inédito en el continente africano. Por su parte, las mujeres estuvieron al frente de la mayor parte de las acciones de separación abiertas en la justicia eclesiástica. Para la historiadora Maria Beatriz Nizza da Silva, pionera en el estudio de estas acciones en la capital paulista, esta preeminencia se explica por las normas morales que regían la conducta de los "dos sexos". Por un lado, favorecían las denuncias femeninas contra malos tratos excesivos. Por otro lado, disuadían a los hombres de hacer público un proceso basado en tales acusaciones. Ningún marido acusaría a su mujer de violentarlo, ya que sería inmediatamente descalificado en su comunidad (Nizza da Silva, 1984, 217) Por su parte, Silvia Brügger cree que, a primera vista, esta primacía también podría leerse de forma más lineal. En otras palabras, como las mujeres eran vistas como más frágiles y sumisas, estaban naturalmente predispuestas a un mayor abuso por parte de sus maridos. Y el predominio de sus peticiones sería una clara consecuencia de su sometimiento al poder masculino. Sin embargo, la autora prefiere apostar por una lectura "más convincente": las esposas tomaban la iniciativa en estas acciones porque, de hecho, ejercían un mayor poder en sus relaciones. Y la práctica de la dote femenina contribuyó en gran medida a ello (Brügger, 1995). 


\section{Juliana Barreto Farias}

Aunque los africanos mina podían considerar muy inapropiado que una mujer quisiera "gobernar a su marido", como decía lo mina Rufino María Balita, no pudieron establecer tranquilamente su poder en las relaciones matrimoniales y familiares, como podían estar acostumbrados en algunas sociedades patriarcales de la costa occidental de África. A este lado del Atlántico, las mujeres tuvieron primacía e independencia en la comunidad negra, destacándose en el control del pequeño comercio urbano y adquiriendo con éxito sus cartas de libertad. Al igual que en otros espacios de la diáspora africana, la esclavitud funcionó como una especie de base para la construcción de un poder ampliamente sexuado. En este sentido, el sexo del amo y del propio esclavo eran factores determinantes en las relaciones desiguales que se constituían. Así, mientras los propietarios no veían ningún impedimento para violar a sus esclavas, a los hombres esclavizados se les negaba sistemáticamente el derecho a ejercer la autoridad sobre sus hijos. Como señala la historiadora Camillia Cowlling (2018), a través del vientre de la mujer, el partus sequitur ventrem, se reforzaba también el poder patriarcal de los amos sobre los hombres esclavizados. ${ }^{26}$ De un modo u otro, aunque generalmente no encajen en las normas de género y en las representaciones ideales impuestas, o esperadas, por la Iglesia y la sociedad, estas mujeres supieron "gobernar" estos recursos a su favor. En Brasil, como en otras regiones de América en general, asistimos a lo que Assunção Lavrin $(1989,7)$ llama un diálogo entre "valores y comportamientos difundidos por la Iglesia y las instituciones del Estado y prácticas y actitudes comunes que transgreden el código moral eclesiástico". En el grupo que analicé, casi todas consiguieron distanciarse, si no para siempre, al menos temporalmente, de los maridos tiranos e incoherentes. Faustina Dourado acabó renunciando a su causa y, en julio de 1860, volvió a vivir con Tiberio Tomás de Aquino. Livia Maria da Purificação no tuvo tanta suerte. Su demanda fue desestimada. Luego recurrió al Tribunal de Apelación de Bahía, donde también fue derrotada. Las otras minas liberadas, al convertirse en mujeres divorciadas, ya no podían volver a casarse en la Iglesia Católica. Pero eso no les impidió cuidar de sus casas y de sus hijos, vender productos en el mercado o en la calle, preservar su patrimonio y quizás encontrar un nuevo amor.

\footnotetext{
${ }^{26}$ Para un análisis de la relación entre género, justicia y legislación en el contexto de la esclavitud, especialmente en el siglo XIX en Río de Janeiro y La Habana, véase el trabajo de Cowling, C. (2018). Sobre las conexiones entre la esclavitud y la libertad en la diáspora y las relaciones de poder basadas en la categoría de género, véase, por ejemplo: Lerner, G. (1983); Morrisey, M. (1989); Scully, P. \& Patton, D. (ed.) (2005).
} 


\section{Bajo el gobierno de las negras minas. Matrimonio y divorcio entre liberados de la costa de África occidental (Río de Janeiro, 1830-1860)}

\section{Bibliografía}

Amadieu, I.(1987). Male daughters, female husbands: gender and sex in African society. London: Zed Books.

Antunes Zanatta, A (2005). Justiça e representações femininas: o divórcio entre a elite paulista (1765-1822). Disertación en Historia, Unicamp.

Barreto Farias, J. (2012). Sob o governo das mulheres: casamento e divórcio entre africanos ocidentais no Rio de Janeiro do século XIX. In: Barreto Farias, J. , Xavier, G.; Gomes, F. (orgs.) Mulheres negras no Brasil escravista e do pós-emancipação. São Paulo: Selo Negro.

Barreto Farias, J. (2012). Fortunata et João José 'parents de nation'. Mariage et divorce chez lês Africans de l'ouest à Rio de Janeiro au XIXe siècle . Brésil(s). Sciences humaines et sociales, (1).

Barreto Farias, J. (2015). Mercados minas: africanos ocidentais na Praça do Mercado do Rio de Janeiro (1830-1890). Rio de Janeiro: Prefeitura da Cidade do Rio de Janeiro-Arquivo Geral da Cidade do Rio de Janeiro.

Barreto Farias, J. (2015). Mercados minas: africanos ocidentais na Praça do Mercado do Rio de Janeiro (1830-1890). Rio de Janeiro: Prefeitura da Cidade do Rio de JaneiroArquivo Geral da Cidade do Rio de Janeiro.

Barreto Farias, J.; Gomes, F. S. \& Soares, C. (2004). Primeiras reflexões sobre travessias e retornos: africanos cabindas, redes do tráfico e diásporas num Rio de Janeiro atlântico . Dossiê: História Atlântica. Textos de História, 12, (1/2).

Brügger, S. (1995). Valores e vivências conjugais: o triunfo do discurso amoroso (bispado do Rio de Janeiro, 1750-1888). Dissertação (Mestrado em História) Universidade Federal Fluminense, Niterói.

Cortês de Oliveira, M. I . (1988). O liberto: o seu mundo e os outros. Salvador: Corrupio.

Cortez de Souza, M. (1999). Crise familiar e contexto social. São Paulo, 1890-1930. Bragança Paulista: EDUSF.

Cowling, C. (2018). Concebendo a liberdade: mulheres de cor, gênero e a abolição da escravidão nas cidades de Havana e Rio de Janeiro. Campinas, SP: Editora da Unicamp. Lerner, G. (1983). Women and slavery. Slavery and Abolition (4), 3.

da Silva Silveira, A. (2005). 0 amor possível: um estudo sobre o concubinato no Bispado do Rio de Janeiro em fins do século XVII e no XIX. Tesis de doctorado. Departamento de Historia de la Unicamp, 2005. 


\section{Juliana Barreto Farias}

de Castelnau-L'Estoile, C. (2011). 0 ideal de uma sociedade escravista cristã: Direito Canônico e matrimônio dos escravos no Brasil colônia. In: Feltier, B.; Souza, E. A Igreja no Brasil. Normas e práticas durante a vigência das Constituições primeiras do Arcebispado da Bahia. São Paulo: Unifesp.

Eltis, D. (2004). The diáspora of yoruba speakers,1650-1865: dimensions and implicantions. In: Falola, T.; Childs, M. (orgs). The yoruba diáspora in the Atlantic World. Bloomington: Indiana University Press.

Falola, T. (1995). Gender, Business and Space Control: Yoruba Women and Power In: House-Midamba, B. and Ekechi, F.K. (eds.). African Market Women and Economic Power: The Role of Women in African Economic Development. Connecticut:Westport.

Faria, S. (2004). Sinhás pretas, damas mercadoras: as pretas minas nas cidades do Rio de Janeiro e de São João del Rei (1700-1850). Tesis para el profesor titular de Historia brasileña, UFF.

Farias, Juliana B.; Gomes, Flávio S.; Soares, C. (2005). No labirinto das nações: africanos e identidades no Rio de Janeiro, século XIX. Rio de Janeiro: Arquivo Nacional.

Florentino, M. (1997). Em costas negras: uma história do tráfico de escravos entre a África e o Rio de Janeiro (séculos XVIII e XIX). São Paulo: Companhia das Letras, 1997.

Gomes, F. \& Soares, C. (2002).'Dizem as quitandeiras'... : ocupações e identidades étnicas numa cidade escravista: Rio de Janeiro, século XIX”. Acervo, 15, (2).

Graham SL. (2011). Being Yoruba in nineteenth-century Rio de Janeiro. Slavery Abol., 32(1).

Graham, S. (2005). Caetana diz não: histórias de mulheres da sociedade escravista brasileira. São Paulo: Companhia das Letras.

Graham, S. (2011). Being yoruba in nineteenth-century Rio de Janeiro. Slavery and Abolition, 32, (1).

Graham, S. (2012). Ser mina no Rio de Janeiro do século XIX. Afro-Ásia, 45

Karasch, M. (2000). A vida dos escravos no Rio de Janeiro (1808-1850). São Paulo: Companhia das Letras.

Lahmeyer Lobo, E. (1978). História do Rio de Janeiro: do capital comercial ao capital industrial e financeiro. Rio de Janeiro: IBMEC.

Lavrin, A. (org.) (1989). Sexuality \& marriage in colonial Latin America. Lincoln: University of Nebraska Press. 


\section{Bajo el gobierno de las negras minas. Matrimonio y divorcio entre liberados de la costa de África occidental (Río de Janeiro, 1830-1860)}

Law, R. (2006). Etnias de africanos na diáspora: novas considerações sobre os significados do termo 'mina. Tempo, 10, (20).

Mendes de Almeida, C. (org.) (1870). Código filipino ou ordenações do reino de Portugal, recompilados por mandado de el rei d. Filipe I ( 1603 ). Rio de Janeiro. Do Instituto Filomático, 1870.

Morrisey, M. (1989). Slave women in the New World: gender stratification in the Caribbean. Lawrence, University Press of Kansas.

Nizza da Silva, M. B. (1984). Sistema de casamento no Brasil colonial. São Paulo: T. A. Queiroz/EDUSP.

Parés, L. (2006). A formação do candomblé: história e ritual da nação jeje na Bahia. Campinas: Editora da Unicamp.

Reis, J. (2008). Domingos Sodré, um sacerdote africano: escravidão, liberdade e candomblé na Bahia do século XIX. São Paulo: Companhia das Letras.

Santana da Silva, M. (1998). As mulheres no Tribunal Eclesiástico do Bispado de Mariana (1748-1830). Disertación en Historia, Unicamp, Campinas.

Santana da Silva, M. (2000). Normas e padrões do Tribunal Eclesiástico Mineiro (1750-1830) e o modo de inserção das mulheres nesse universo jurídico. História Social, 7.

Scully, P. \& Patton, D.(ed.) (2005). Gender and slave emancipation in the Atlantic world. Durham: Duke University Press.

Soares, C. (2001). A capoeira escrava e outras tradições rebeldes (1808-1850). Campinas: Editora da Unicamp.

Soares, C. (2005). "A 'nação' da mercancia: Condição feminina e as africanas da Costa da Mina, 1835-1900”. In: Farias, Juliana B.; Gomes, Flávio S.; Soares, C. No labirinto das nações: africanos e identidades no Rio de Janeiro, século XIX. Rio de Janeiro: Arquivo Nacional.

Soares, C.; Gomes, F. (2007). Dos S. Negras minas no Rio de Janeiro: gênero, nação, e trabalho urbano no século XIX. In: Soares, M. Rotas atlânticas da diáspora africana: da Baía do Benin ao Rio de Janeiro. Niterói: Editora da UFF.

Soares, M. (2000). Devotos da cor: identidade étnica, religiosidade e escravidão no Rio de Janeiro. Rio de Janeiro: Civilização Brasileira. 


\section{Juliana Barreto Farias}

Soares, U. (2006). Os processos de divórcio perpétuo nos séculos XVIII e XIX: entre o sistema de aliança e o regime da sexualidade. Tesis de doctorado en Historia, UFRGS, Porto Alegre.

Vide, S. (2010). Constituições primeiras do Arcebispado da Bahia. Edição organizada por Bruno Feltier e Evergton Sales Sousa. São Paulo: Edusp.

Arquivo da Cúria Metropolitana do Rio de Janeiro

Recibido: 01/07/2021

Evaluado: 03/08/2021

Versión Final: 14/08/2021 